\title{
Simulation of Cellular Remodeling: from Cardiac Myofiber to Whole Heart
}

Ani Amar*

Department of Biomedical Engineering, Faculty of Engineering, Tel Aviv University, Israel

Article Info

\section{Article Notes}

Received: May 01, 2018

Accepted: July 06, 2018

\section{${ }^{*}$ Correspondence:}

Dr. Ani Amar, Department of Biomedical Engineering, Faculty of Engineering, Tel Aviv University, Israel; Telephone No: +972506971292; E-mail: anizak@post.tau.ac.il.

(c) 2018 Amar A. This article is distributed under the terms of the Creative Commons Attribution 4.0 International License

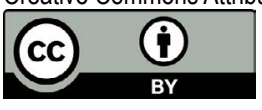

\section{Keywords:}

Cardiac myofiber

Heart failure

Mathematical model

Cardiac electrophysiology

\section{ABSTRACT}

Heart failure is characterized as any heart condition resulting from impairment of the heart's ability to pump blood, with high prevalence in both aged and diseased hearts. Numerous population-based studies have shown that, in patients with impaired left ventricular systolic function, additional structural and functional cardiovascular abnormalities are often found, making it difficult to understand the underlying pathophysiological processes. Advances in experimental and modeling tools have led to the identification of many cellular mechanisms that contribute to cardiac failure. Still, the mechanism by which cardiac myofiber adaptation ultimately leads to failure remains unclear. Several human cell, tissue, and organ models are used to model heart failure. In this mini review, several available human models are summarized with a focus on the simulation of cellular remodeling: from membrane excitation at the level of the single cell to contraction of the ventricle.

Despite substantial progress in experimental and modeling tools, the understanding of the underlying pathophysiological processes in cardiac tissue is still limited due to the difficulty in direct measurements of the mechanical and electrical processes within the contracting heart. Multiple models of individual muscle cells (cardiac myofibers or myocytes) have been established to clarify the nature and pathogenesis of heart diseases. These models, which simulate cellular electrical, and mechanical activity, can be integrated into organ level cardiac models to study the contribution of interrelated cellular mechanisms to global myocardial function in both normal and disease conditions.

One of the most common heart disease conditions is heart failure (HF), which reduces the ability of the heart to pump blood ${ }^{1}$. Because $\mathrm{HF}$ is highly prevalent in both aged and diseased hearts ${ }^{2}$, it has become the subject of numerous models at the single-cell ${ }^{3-6}$, tissue ${ }^{7-9}$, and whole-heart levels ${ }^{10-14}$. Each of these models has different experimental data basis, accuracy, ability to account for underlying physiology and computational efficiency. Despite considerable development of these models, the great challenge remains to describe the mechanisms of $\mathrm{HF}$ in humans due to the limited availability of human data.

\section{Simulation of Cellular Remodeling in the Failing Myocyte}

The electrophysiological remodeling under $\mathrm{HF}$ condition is associated with action potential (AP) prolongation and altered calcium $\left(\mathrm{Ca}^{2+}\right)$ handling in animal models and humans ${ }^{15}$. Several human electrophysiological models are capable of simulating these events by changing the maximal conductances or scaling factors of particular ion currents $^{4-7}$. For example, in these models, the density of the transient outward potassium current $\left(I_{\text {to }}\right)$, which contributes significantly to AP prolongation ${ }^{16}$, is reduced by $33-60 \%$. The reduction of the inward rectifier potassium current $\left(I_{K 1}\right)$ in the models $(\downarrow 25-50 \%)$ contributes 
to the reduced resting membrane potential, which has been reported in human studies ${ }^{16,17}$. Few models consider the downregulation $(\downarrow 40-50 \%)$ of a slow component of the delayed rectifier potassium current $\left(I_{\mathrm{KS}}\right)$ as an important contributor to the late phase of repolarization. Altered calcium $\left(\mathrm{Ca}^{2+}\right)$ handling in the electrophysiological models is commonly simulated by sarcolemmal sodiumcalcium exchanger $\left(I_{\mathrm{NaCa}}\right)$ upregulation ( $\left.\uparrow 36-200 \%\right)$ and sarcoplasmic reticulum $\mathrm{Ca}^{2+}$ (SERCA) pump downregulation ( $\downarrow 40-50 \%)$, as is observed in human $\mathrm{HF}^{18,19}$.

If the objective of a particular research requires remodeling of three transmural cell types-epicardial (epi), mid-myocardial (M cells), and endocardial cells (endocells)-there is another group of models ${ }^{3,4,20-22}$ that have been developed based on existing electrophysiological models of undiseased human ventricular cells: the Ten Tusscher-Noble-Noble-Panfilov (TNNP) model ${ }^{23,24}$, the O'Hara-Virág-Varró-Rudy (OVVR) model ${ }^{25}$, and the GrandiPasqualini-Bers (GPB) model (for epi- and endo-cells only ${ }^{26}$. Transmural remodeling can be incorporated using the mentioned alterations of the transmembrane currents for each cell type. Table 1 contains several characteristics of these models (i.e., the sources of experimental data of the remodeled currents and exchangers, ventricular cell type, the number of variables and integration time step, and the models on which they are based).

The consequences of AP prolongation include elevated intracellular $\mathrm{Ca}^{2+},{ }^{27}$ which, in turn, increases contractility as a compensatory response of the heart to an increased load ${ }^{15}$. On the other hand, chronic elevation in intracellular $\mathrm{Ca}^{2+}$ resulting from AP prolongation may lead to the maladaptive expression of genes encoding $\mathrm{Ca}^{2+}$-handling proteins [e.g., SERCA, ryanodine receptor (RyR2) $]^{19}$. In both cases, the muscle contractile process, which involves the interaction of myofilaments (actin and myosin) in the presence of $\mathrm{Ca}^{2+}$, is compromised by impaired $\mathrm{Ca}^{2+}$ handling.

To simulate a disturbance in excitation-contraction coupling, the changes related to HF can be incorporated into the cellular myofilament models. Notably, the investigators of one study by Adeniran et al. ${ }^{11}$ have examined the cellular mechanisms influencing myocardial $\mathrm{Ca}^{2+}$ homeostasis in $\mathrm{HF}$ with preserved ejection fraction using an electromechanical single cell model in the 3D multiscale model of the human left ventricle. The authors altered passive forces arising from titin and collagen in the myofilament model $^{28}$, which represent the active tension generation within each myocyte, thereby influencing the contractile force. The study also includes simulations of structural remodeling of the left ventricular wall. The results of this study emphasize the reduction in sodium-calcium exchange $\left(I_{\mathrm{NaCa}}\right)$ activity as a dominant factor leading to impaired $\mathrm{Ca}^{2+}$ handling and diastolic dysfunction in patients with HF-preserved ejection fraction. Additionally, the results indicate the role of impaired $\mathrm{Ca}^{2+}$ homeostasis in abnormalities of left ventricle contraction and relaxation.

\section{Whole-Heart Simulation of Heart Failure}

There are several multiscale electromechanical models aimed at investigating the effects of HF-induced intracellular remodeling on global ventricular function.

Table 1: Electrophysiological models of failing human ventricular myocytes

\begin{tabular}{|c|c|c|c|c|c|}
\hline Study & Cardona et al..$^{\beta}$ & Trenor et al. $\left.\right|^{\mid 4}$ & Elshrif et al. $\left.\right|^{20}$ & Walmsley et al. $\left.\right|^{21}$ & Lu et al. $\left.\right|^{22}$ \\
\hline Model based on & $\begin{array}{l}\text { modified } \\
\text { GPB model }\end{array}$ & $\begin{array}{l}\text { modified } \\
\text { GPB model }\end{array}$ & $\begin{array}{l}\text { modified } \\
\text { OVVR model }\end{array}$ & $\begin{array}{l}\text { modified } \\
\text { OVVR model }\end{array}$ & $\begin{array}{l}\text { modified } \\
\text { TNNP model }\end{array}$ \\
\hline Cell type & not specified & Endo $^{a}$ & $\begin{array}{l}\text { Epi }^{\mathrm{b}} \\
\text { Endo, } \mathrm{M}^{\mathrm{c}}\end{array}$ & Endo & M \\
\hline Number of variables & 38 & 38 & 41 & 41 & 17 \\
\hline Integration time step & not specified & not specified & $\begin{array}{l}0.02 \mathrm{~ms} \\
\text { (0.001 ms for calcium } \\
\text { equations) }\end{array}$ & not specified & $0.01 \mathrm{~ms}$ \\
\hline Experimental data basis & $\begin{array}{l}\mathrm{I}_{\mathrm{NaL}}(A)^{\mathrm{d}}, \\
\mathrm{I}_{\text {to }}(\mathrm{A} \& \mathrm{H}), \\
\mathrm{I}_{\mathrm{K} 1}(\mathrm{~A} \& \mathrm{H}), \\
\text { SERCA }(\mathrm{H}) \\
\mathrm{I}_{\mathrm{NaCa}}(\mathrm{A}), \\
\mathrm{I}_{\mathrm{NaK}}(\mathrm{H}), \\
\mathrm{I}_{\text {leak }}(\mathrm{H}), \\
\mathrm{EC}_{50 \mathrm{R}}(\mathrm{H}), \\
\mathrm{I}_{\mathrm{Cab}}(\mathrm{H}), \\
\mathrm{I}_{\mathrm{Nab}}(\text { model fit })\end{array}$ & 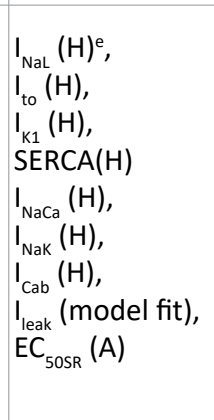 & $\begin{array}{l}\mathrm{I}_{\mathrm{Na}}(\mathrm{H}), \\
\mathrm{I}_{\mathrm{NaL}}(\mathrm{H}), \\
\mathrm{I}_{\text {to }}(\mathrm{H}), \\
\mathrm{I}_{\mathrm{K} 1}(\mathrm{H}) \\
\mathrm{I}_{\mathrm{Kr}}(\mathrm{A} \& H) \\
\mathrm{I}_{\mathrm{KS}}(\mathrm{A} \& H) \\
\text { SERCA }(H) \\
\mathrm{I}_{\mathrm{NaCa}}(\mathrm{H}) \\
\mathrm{I}_{\mathrm{NaK}}(\mathrm{H})\end{array}$ & $\begin{array}{l}\mathrm{I}_{\mathrm{CaL}}(\mathrm{H}), \\
\mathrm{I}_{\text {to }}(\mathrm{H}), \\
\mathrm{I}_{\mathrm{Kr}}(\mathrm{H}), \\
\mathrm{I}_{\mathrm{Ks}}(\mathrm{H}), \\
\text { SERCA }(\mathrm{H}), \\
\mathrm{I}_{\mathrm{NaCa}}(\mathrm{H})\end{array}$ & $\begin{array}{l}\mathrm{I}_{\mathrm{Na}}(\mathrm{A}) \text {, } \\
\mathrm{I}_{\mathrm{to}}(\mathrm{H}), \\
\mathrm{I}_{\mathrm{K} 1}(\mathrm{H}), \\
\mathrm{I}_{\mathrm{Ks}}(\mathrm{A}) \text {, } \\
\text { SERCA }(\mathrm{H}), \\
\mathrm{I}_{\mathrm{NaCa}}(\mathrm{H}), \\
\mathrm{I}_{\mathrm{NaK}}(\mathrm{H}), \\
\mathrm{I}_{\mathrm{bCa}} \\
\text { (model fit), } \\
\text { RyR2 (H) }\end{array}$ \\
\hline \multicolumn{6}{|c|}{$\begin{array}{l}\text { a Endo-endocardial cell; }{ }^{b} \text { Epi - epicardial cell; }{ }^{c} \mathrm{M} \text { - midmyocardial cell } \\
\text { d (A) experiments on failing animal cardiomyocytes } \\
\text { e (H) experiments on failing human ventricular myocytes }\end{array}$} \\
\hline
\end{tabular}


Each model uses different microscopic and macroscopic anatomy representation and different levels of biophysical detail of the subcellular/cellular models. Common features among the whole-heart models are the electrical and mechanical components and their coupling by intracellular $\mathrm{Ca}^{2+}$ released during electrical activation. The models differ, however, regarding geometrical structure, which is usually selected based on the objectives of the particular research. The investigator's choice thus lies between simplified 3D geometries such as elliptical geometries ${ }^{11,14}$ and anatomically accurate geometries ${ }^{10,12,13}$.

In one study ${ }^{14}$, the 3D model structure represents the left ventricle with one layer of myocardial fibers (midmyocardium, as a significant contractile layer). Notably, this 3D fiber-based model of the contracting ventricle uses a non-continuum approach to represent the myocardium. In this model, each individual fiber can be controlled, and blood elements are included to represent the resistance of intraventricular blood to ventricular contraction. In this configuration, each blood element is connected to a nodal point on the inner ventricle at one end and the center of volume of the intraventricular space at the other end. In contrast, in most other models, blood is represented as boundary conditions on the ventricles, and hence, blood pressure or flow parameters are inputs, rather than outputs, of the simulations.

Other models use the segmentation of the heart wall to account for the transmural heterogeneity (epi-, $\mathrm{M}$, endo- layers) ${ }^{11-13}$ based on experimental data ${ }^{29,30}$. In anatomically accurate models, anatomical details were obtained by individual heart geometries using magnetic resonance (MR) imaging data ${ }^{12,13}$. The models used a rulebased approach ${ }^{30-32}$ to generate the myocardial fiber and sheet directions. The model of Moreno and coworkers ${ }^{12}$ incorporated ionic conductivity changes to the normal values from the TNNP model ${ }^{24}$, including a Markovian representation of the cardiac sodium channel $\left(I_{\mathrm{Na}}\right)$, to model $\mathrm{HF}$ in 3D human ventricular models. The image-based computational model of the human ventricles ${ }^{33}$ served as a geometrical basis for the evaluation of the conditions under which the anti-arrhythmic drugs flecainide and lidocaine will prevent or exacerbate arrhythmia. The simulation results demonstrated that reentrant arrhythmias could be initiated even if an ectopic stimulus occurs outside of the "vulnerable window" for flecainide, but not for lidocaine. This is due to lidocaine-blocked sodium channels which showed faster recovery from drug blockage. These results have important implications for the modeling approaches toward the pharmacologic treatment of cardiac arrhythmias.

The study by Sanchez-Alonso et al. ${ }^{13}$ examined microdomain-specific remodeling of L-type $\mathrm{Ca}^{2+}$ channels in $\mathrm{HF}$ within the $3 \mathrm{D}$ human left ventricle mode ${ }^{33}$ by analyzing the resulting early afterdepolarizations (EADs). For this purpose, the human ventricular cell electrophysiological
OVVR mode ${ }^{25}$ was extended by adding Markovian representation of the L-type $\mathrm{Ca}^{2+}$ current, implementing $\mathrm{HF}$ ion channel remodeling based on Elshrif et al. ${ }^{20}$. Simulations of EADs in control and in failing endo- and epicardial cells in this model revealed the development of EADs only in failing endo cells and, subsequently, an endocardial EAD trigger formation in whole-heart simulations in HF. The authors concluded that HF-induced L-type $\mathrm{Ca}^{2+}$ channel remodeling and subcellular changes can lead to the occurrence of arrhythmogenic triggers or arrhythmias at the organ level.

Both studies ${ }^{12,13}$ used image-based individual geometries ${ }^{33}$ for the evaluation of the cellular and tissue models under HF. The main advantage of MR imaging data includes the fiber and laminar sheet structure information for individual ventricular geometry, which is of critical importance when modeling diseased hearts. In addition, MR imaging data acquisition procedure is considerably less time- and resourceintensive compared to histological sectioning. Despite these advantages, most MRI-based whole-heart models do not include the representation of the spatially varied structural remodeling that occurs as a result of HF.

\section{Conclusions}

The efforts towards simulation of cellular remodeling associated with HF in the papers reviewed above show significant progress both at cardiac myofiber level and whole-heart level. The development of advanced, high quality experimental methods is a challenging, but necessary step towards further extension of multiscale models. While cellular remodeling process predicted though simulation studies is valuable, particularly for the understanding of the complex pathophysiological factors that underlie $\mathrm{HF}$, reconstructions of structural remodeling from MR images provide a framework in which predictions can be reliably ascertained. However, this approach has not yet been widely adopted due to the complexity and large computational requirements of the models.

\section{Conflicts of interests}

The author has no potential conflicts of interests to disclose.

\section{Sources of funding}

None.

\section{References}

1. Guyton AC, Hall JE. Textbook of medical physiology.11th ed. Elsevier Saunders Philadelphia Pennsylvania. 2006.

2. Mosterd A, Hoes AW. Clinical epidemiology of heart failure. Heart. 2007; 93: 1137-1146.

3. Cardona K, Gómez J, Ferrero J, et al. Simulation study of the electrophysiological mechanisms for heart failure phenotype. Computing in Cardiology IEEE. 2011; 461-464.

4. Trenor B, Cardona K, Gomez JF, et al. Simulation and 
mechanistic investigation of the arrhythmogenicrole of the late sodium current in human heart failure. PLoS ONE. 2012; vol. 7, no. 3: e32659.

5. Priebe L, Beuckelmann DJ. Simulation study of cellular electric properties in heart failure. Circulation Res. 1998; vol. 82, no.11: 1206-1223.

6. Shannon T, Wang F. Bers. Regulation of cardiac sarcoplasmic reticulum $\mathrm{Ca}$ release by luminal [Ca] and altered gating assessed with a mathematical model. Biophys J. 2005; 89: 4096-4110.

7. Zlochiver S. Subthreshold parameters of cardiac tissue in a bilayer computer model of heart failure. Cardiovasc Eng. 2010; 10:190-200.

8. Narayan SM, Bayer JD, Lalani G, et al. Action potential dynamics explain arrhythmic vulnerability in human heart failure: A clinical and modeling study implicating abnormal calcium handling. J Am College Cardiol. 2008; vol. 52, no. 22: 1782-1792.

9. Gomez JF, Cardona K, Romero L, et al. Electrophysiological and structural remodeling in heart failure modulate arrhythmogenesis. 1d simulation study. PLoS ONE. 2014; vol. 9, no. 9: e106602.

10. Cai L, Wang Y, Gao H, et al. A mathematical model for active contraction in healthy and failing myocytes and left ventricles. PLoS One. 2017;12: e0174834. pmid:2840699.

11. Adeniran I, MacIver DH, Hancox JC et al. Abnormal calcium homeostasis in heart failure with preserved ejection fraction is related to both reduced contractile function and incomplete relaxation: an electromechanically detailed biophysical modeling study. Front. Physiol. 2015; 6:78. doi: 10.3389/ fphys.2015.00078.

12. Moreno JD, Zhu ZI, Yang PC, et al. A computational model to predict the effects of class I anti-arrhythmic drugs on ventricular rhythms. Sci. Translational Med. 2011; vol. 3, no. 98: 98ra83.

13. Sanchez-Alonso JL, Bhargava A, O'Hara T, et al. MicrodomainSpecific Modulation of L-type Calcium Channels Leads to Triggered Ventricular Arrhythmia in Heart Failure. Circ Res. 2016; pmid:27572487.

14. Amar A, Zlochiver S, Barnea O. Mechano-electric feedback effects in a three-dimensional (3D) model of the contracting cardiac ventricle. PLoS ONE. 2018; 13(1): e0191238. https:// doi.org/10.1371/journal.pone.0191238.

15. Wickenden AD, Kaprielian R, Kassiri Z, et al. The role of action potential prolongation and altered intracellular calcium handling in the pathogenesis of heart failure. Cardiovasc Res. 1998; 37:312-323.

16. Beuckelmann DJ, Näbauer M, Erdmann E, et al. Alterations of $\mathrm{k}+$ currents in isolated human ventricular myocytes from patients with terminal heart failure. Circulation Res. 1993; vol. 73 , no. 2: 379-385

17. Li GR, Lau CP, Leung TK, et al. Ionic current abnormalities associated with prolonged action potentials in cardiomyocytes from diseased human right ventricles. Heart Rhythm. 2004; 1 : 460-468.
18. Studer R, Reinecke H, Bilger J, et al. Gene expression of the cardiac $\mathrm{Na}+-\mathrm{Ca} 2+$ exchanger in end-stage human heart failure. Circ Res. 1994;75:443-453.

19. Hasenfuss G, Meyer M, Schillinger W, et al. Calcium handling proteins in the failing human heart. Basic Res Cardiol 1997;.92_1:87-93.

20. Elshrif MM, Shi P, Cherry EM. Representing variability and transmural differences in a model of human heart failure. IEEE. 2015; 19: 1308-1320.

21. Walmsley J, Rodriguez JF, Mirams GR, et al. mRNA expression levels in failing human hearts predict cellular electrophysiological remodeling: A population-based simulation study. PLoS ONE. 2013; v ol. 8, no. 2: e56359.

22. Lu L, Xia L, Zhu X, et al. Simulation of arrhythmogenic effect of rogue RyRs in failing heart by using a coupled model. Comput. Math. Methods Med. 2012; 9: e106602.

23. Ten Tusscher KHWJ, Noble D, Noble PJet al. A model for human ventricular tissue. Am J Physiol Heart Circ Physiol. 2004; 286: H1573-H1589.

24. ten Tusscher KH, Panfilov AV. Alternans and spiral breakup in a human ventricular tissue model. Am J Physiol Heart Circ Physiol. 2006; 291 (3): H1088.

25. O’Hara T, Virág L, Varró A, et al. Simulation of the Undiseased Human Cardiac Ventricular Action Potential: Model Formulation and Experimental Validation. PLoS Comput Biol. 2011; 7(5): e1002061. doi:10.1371/journal.pcbi.1002061.

26. Grandi E, Pasqualini FS, Bers DM. A novel computational model of the human ventricular action potential and $\mathrm{Ca}$ transient. J Mol Cell Cardiol. 2010; 48(1):112-21.

27. Bouchard RA, Clark RB, Giles WR. Effects of action potential duration on excitation-contraction coupling in rat ventricular myocytes. Action potential voltage-clamp measurements. Circ Res. 1995;76:790-801.

28. Tran K, Smith NP, Loiselle DS, et al. A metabolite- sensitive, thermodynamically constrained model of cardiac cross-bridge cycling: implications for force development during ischemia. Biophys J. 2010; 98: 267-276. doi:10.1016/j.bpj.2009.10.011

29. Drouin E, Charpentier F, Gauthier C, et al. Electrophysiologic characteristics of cells spanning the left ventricular wall of human heart: evidence for presence of M cells. J Am Coll Cardiol. 1995; 26: 185-192. doi:10.1016/0735-1097(95)00167-X.

30. Glukhov AV, Fedorov VV, Lou Q, et al. Transmural dispersion of repolarization in failing and nonfailing human ventricle. Circ Res. 2010; 106 (5): 981.

31. Bayer JD, Blake RC, Plank G, et al. A novel rule-based algorithm for assigning myocardial fiber orientation to computational heart models. Ann Biomed Engineering. 2012; 40: 2243-2254.

32. Wang H, Gao H, Luo X, et al. Structure-based finite strain modelling of the human left ventricle in diastole. International journal for numerical methods in biomedical engineering. 2013; 29(1): 83 \pm 103 . https://doi.org/10.1002/cnm.2497 PMID: 23293070.

33. Vadakkumpadan F, Arevalo H, Prassl AJ, et al. Image-based models of cardiac structure in health and disease. Wiley Interdiscip Rev Syst Biol Med. 2010; 2(4): 489. 